\title{
Failure Analysis Case Study on a Fractured Tailwheel Fork
}

\author{
Jonathan Carlos Contreras • Sylvia Lucia Natividad • \\ Stephen William Stafford
}

Submitted: 24 March 2011/Published online: 24 May 2011

(C) ASM International 2011

\begin{abstract}
A failure analysis investigation was conducted on a fractured aluminum tailwheel fork which failed moments after landing of a privately owned, 1955 twin-engine airplane. Non-destructive evaluation via dye-penetrant inspection revealed no discernible surface cracks. The chemical composition of the sand-cast component was identified via optical emission spectroscopy and is comparable to an aluminum sand-cast alloy, AA 712.0. Metallographic evaluation via optical microscopy and scanning electron microscopy revealed a high degree of porosity in the microstructure as well as the presence of deleterious intermetallic compounds within interdendritic regions. Macro-hardness testing produced hardness values which are noticeably higher than standard hardness values for 712.0. The primary fracture surfaces indicate evidence of mixed mode fracture, via intergranular cracking, cleaved intermetallic particles, and dimpled cellular regions in the matrix. The secondary fracture surface demonstrates similar features of intergranular fracture.
\end{abstract}

Keywords Aluminum casting · Failure analysis · Fracture

\section{Introduction}

The failure of the subject component occurred moments after landing on a landing strip in Las Cruces, NM, prior to a complete stop of the airplane in February of 2009.

J. C. Contreras $(\bowtie) \cdot$ S. L. Natividad · S. W. Stafford

The University of Texas at El Paso-Metallurgical and Materials

Engineering, Engineering Bldg., Room M-201 500 W.

University Ave., El Paso, TX 79968-0521, USA

e-mail: jccontreras@miners.utep.edu
Figures 1, 2, and 3 demonstrate the three tailwheel fork pieces that were retrieved by the airplane pilot/owner shortly after failure of the component: the right-side fork leg (relative to the nose of the airplane), the left-side axle pin joint, and the remnant body of the fractured tailwheel fork. It was reported that the tailwheel and the right-side fork leg were found still attached, the left-side axle pin joint was found on the landing strip, and the remnant body of the fractured tailwheel fork was still attached to the airplane after failure. The mechanical damage on the left-side fork leg is attributed to attritional damage as a consequence of the component remaining attached to the airplane as it came to a stop during landing. Figure 4 demonstrates a photograph of the component attached to the body of the airplane, as it would have appeared in service.

The dimensions of the component can be seen in Fig. 5, which are drawings generated by measured and extrapolated component dimensions.

\section{Experimental Procedure}

Non-destructive evaluation of the tailwheel component was done via liquid dye-penetrant examination. Each retrieved piece of the component was sprayed with a cleaner/ remover and allowed to sit for $30 \mathrm{~min}$. The pieces were then sprayed with dye penetrant and left to fully absorb the dye for $30 \mathrm{~min}$. After wiping down the parts, the developer was added and the pieces were observed for $30 \mathrm{~min}$ so as to detect the appearance of any discernible surface defects.

Chemical analysis to determine the component's chemical composition was conducted via certified optical emission spectroscopy (OES).

Axial and transverse sections from the right-side fork leg were cold mounted in resin for metallographic 


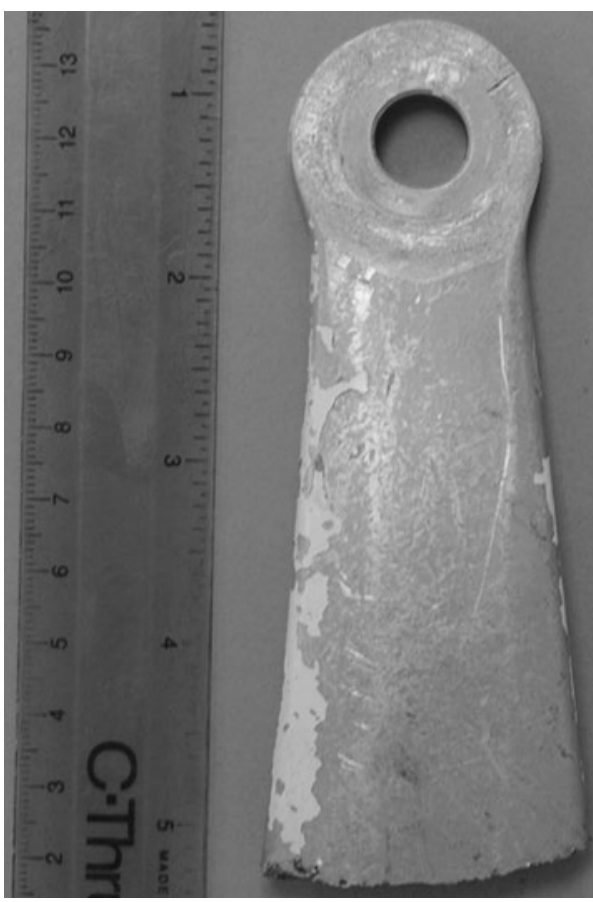

Fig. 1 Fractured right-side fork leg

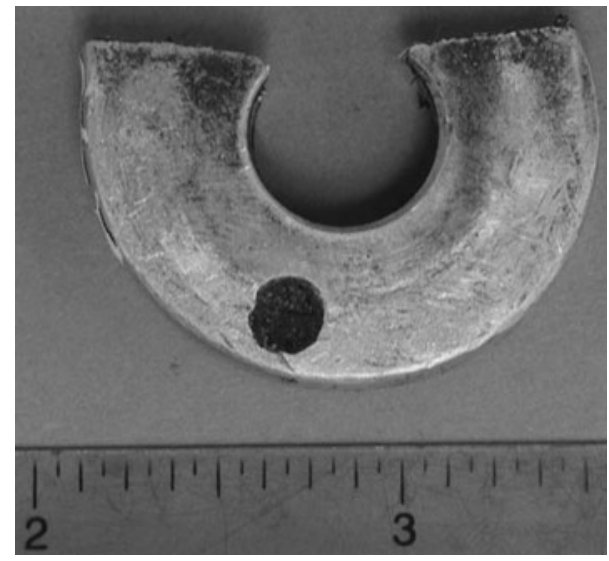

Fig. 2 Fractured left-side axle pin joint

inspection. The metallographic mounts were polished and etched in order to view the microstructure through optical and scanning electron microscopy. Sample grinding was conducted with silicone carbide pads, from 240 through 1200 grit. Polishing was done with $1,0.3$, and $0.05 \mu \mathrm{m}$ alumina powders, along with 4 and $1 \mu \mathrm{m}$ diamond pastes. The sample was cleaned in ethanol for $2 \mathrm{~min}$ in between each alumina powder and diamond paste polishing, and finally on completion of polishing. Keller's reagent, commonly used in etching aluminum alloys, was used for this sample and applied to the surface for approximately $15 \mathrm{~s}$ with a cotton swab. The primary fracture surfaces were cleaned in ethanol for $5 \mathrm{~min}$. The secondary fracture

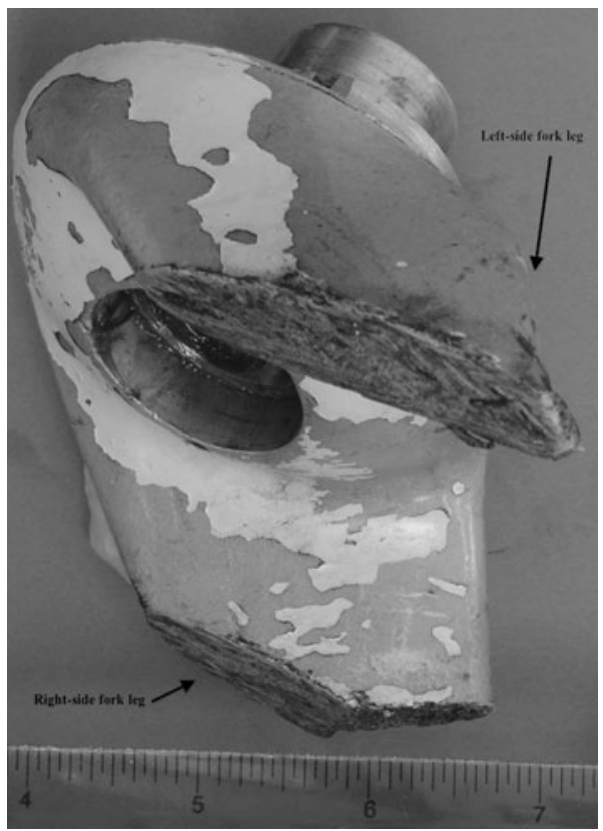

Fig. 3 Remnant body of the fractured tailwheel fork

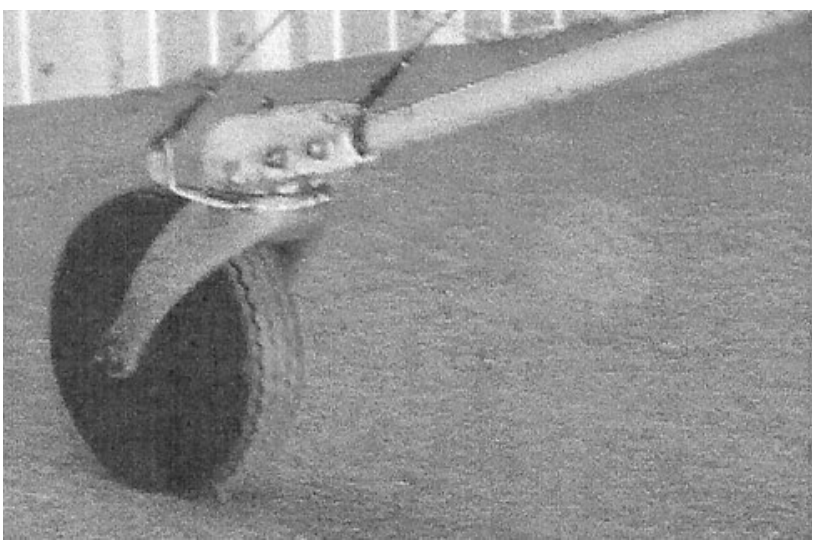

Fig. 4 Right-side view of fork component attached to tailwheel, as it was assembled in service

surfaces required the use of $15 \mathrm{~g}$ of a water-based detergent in $350 \mathrm{~mL}$ of de-ionized water at a temperature of $95^{\circ} \mathrm{C}$. The samples were left in the bath while being ultrasonically agitated for $30 \mathrm{~min}$, with regular visual progress inspections throughout the process.

The fracture surfaces (samples A-D), along with the polished metallographic mounts, were analyzed in the scanning electron microscope. Macro-hardness measurements were taken on the metallography sample in the Rockwell E scale, prior to it being mounted, polished, and etched.

Model drawings of the component (Fig. 5) were generated using Unigraphics NX 6 software. A stress analysis of the component was done via FEA using Unigraphics NX Nastran software, with a mesh size of $9.92 \mathrm{~mm}$. 
Fig. 5 Multiple views of reconstructed component drawing

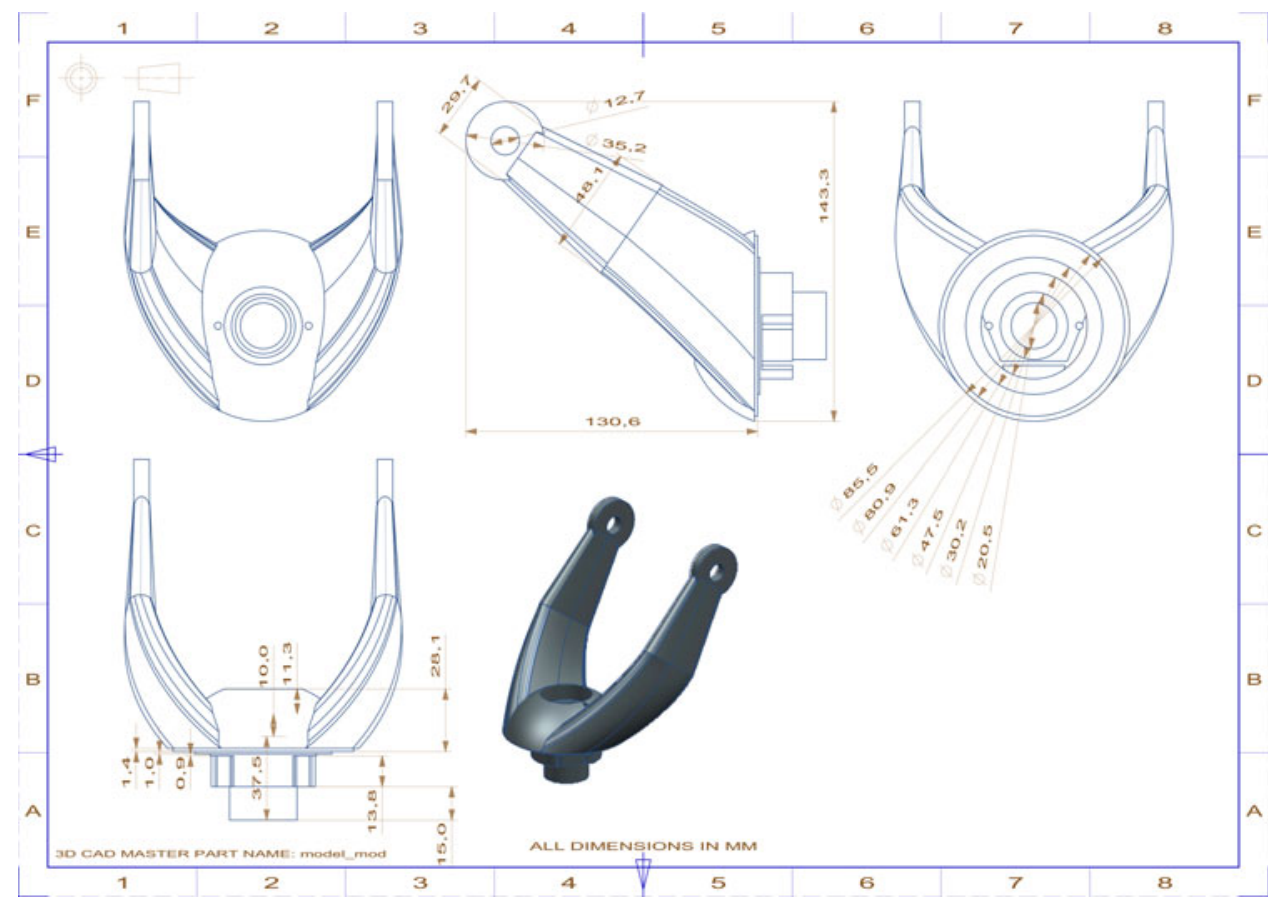

\section{Results and Discussion}

Non-Destructive Testing

Two dye-penetrant inspections of the component pieces did not indicate any discernible surface discontinuities on any of the pieces.

\section{Chemical Analysis}

OES was used to determine the composition of the component; the results of this analysis can be seen in Table 1 . The aluminum alloy that best matches the chemical composition of the bulk OES sample is a sand-cast aluminum alloy, AA 712.0. The chemical composition of this alloy, according to ASTM Standard B26, can be found in Table 2 [1]; when single units are shown in Table 2, these indicate the maximum amounts permitted.

On the comparison of Tables 1 and 2, it is seen that copper and titanium are the only elements that are not in conformance with ASTM Standard B26; the rest of the elements either fall in their allowable amount ranges or they are below their maximum allowable limits. The amount of copper permitted is nearly twice that value in the component. The titanium content in the component barely passes the maximum allowable limit, by $0.02 \mathrm{wt} . \%$. All other amounts of elements not explicitly specified by ASTM Standard B26 do not sum to more than $0.2 \mathrm{wt} . \%$, are not $>0.05 \mathrm{wt} . \%$ for each element, and hence are in compliance.
Table 1 OES chemical analysis from representative section of component

\begin{tabular}{ll}
\hline Element & \multicolumn{1}{c}{ Wt.\% } \\
\hline Aluminum & Remainder \\
Zinc & 5.22 \\
Magnesium & 0.63 \\
Chromium & 0.41 \\
Iron & 0.26 \\
Manganese & 0.01 \\
Silicon & 0.09 \\
Copper & 0.58 \\
Titanium & 0.27 \\
Nickel & $<0.01$ \\
Lead & $<0.01$ \\
Tin & $<0.01$ \\
Beryllium & $<0.01$ \\
Vanadium & 0.01 \\
Zirconium & $<0.01$ \\
\hline
\end{tabular}

\section{Mechanical Testing}

The right-fork leg was sectioned so as to remove the secondary fracture surface for SEM viewing; the remnant right-fork leg was further sectioned in order to produce a sample for macro-hardness testing and OES analysis (Fig. 6). The hardness on both sides of the sectioned piece were nearly identical, with an average value being $68 \mathrm{HRB}$, which converts into $103 \mathrm{BHN}$ (500 kgf, $10 \mathrm{~mm}$ ball). The expected hardness of as-cast AA 712.0 aluminum alloy, in 
Table 2 Chemical composition of AA 712.0 [1]

\begin{tabular}{ll}
\hline Element & \multicolumn{1}{c}{ Wt.\% } \\
\hline Aluminum & Remainder \\
Zinc & $5.0-6.5$ \\
Magnesium & $0.50-0.65$ \\
Chromium & $0.40-0.6$ \\
Iron & 0.50 \\
Manganese & 0.10 \\
Silicon & 0.30 \\
Copper & 0.25 \\
Titanium & $0.15-0.25$ \\
Nickel & N/A \\
\hline
\end{tabular}

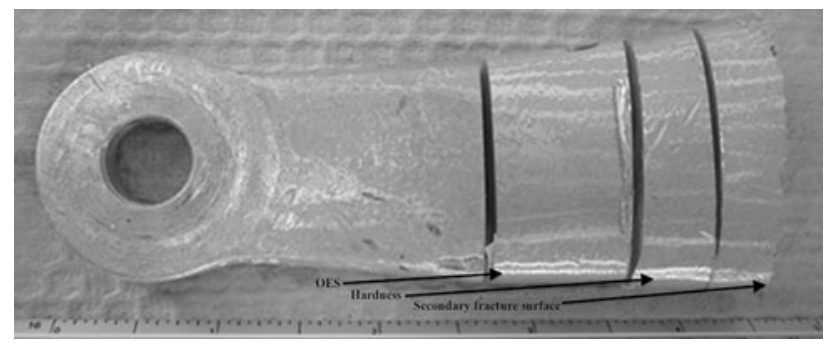

Fig. 6 Sectioned right-side fork leg

the T5 temper condition, is 75 BHN according to ASTM's standard B26.

A T5 temper for AA 712.0 can be achieved by aging at $24{ }^{\circ} \mathrm{C}$ for 21 days or by aging at $157{ }^{\circ} \mathrm{C}\left( \pm 5^{\circ} \mathrm{C}\right)$ for $6-8 \mathrm{~h}$, according to ASTM's standard B917 [2]. This will produce the following minimum mechanical property values in the material: $34 \mathrm{ksi}$ tensile strength and $4 \%$ elongation in $50 \mathrm{~mm}$ [1]. Tensile tests conducted on AA 712.0 samples, after being exposed to four different aging temperatures $\left(24,79,120\right.$, and $\left.180{ }^{\circ} \mathrm{C}\right)$ for $1000 \mathrm{~h}$, indicate that both the minimum values for tensile strength and elongation in $50 \mathrm{~mm}$ decreased as the aging temperature increased [3]. As tensile ductility and hardness are usually inversely related, this data indicates that this material can naturally overage with time, at temperatures higher than room temperature. This observation is substantiated by Hatch [3], as he indicates that "the tensile properties of the aluminumzinc-magnesium alloys in the as-cast ( $\mathrm{F}$ temper) condition change rapidly during the first few weeks of room temperature aging, because of natural precipitation hardening. Additional hardening continues thereafter at a progressively slower rate."

After 54 years of service, it is expected that the component was exposed to service temperatures in excess of $24{ }^{\circ} \mathrm{C}$, as the known aircraft history places the majority of its flights in the American Southwest for 30 years. As a consequence, the natural aging mechanism inherent to the

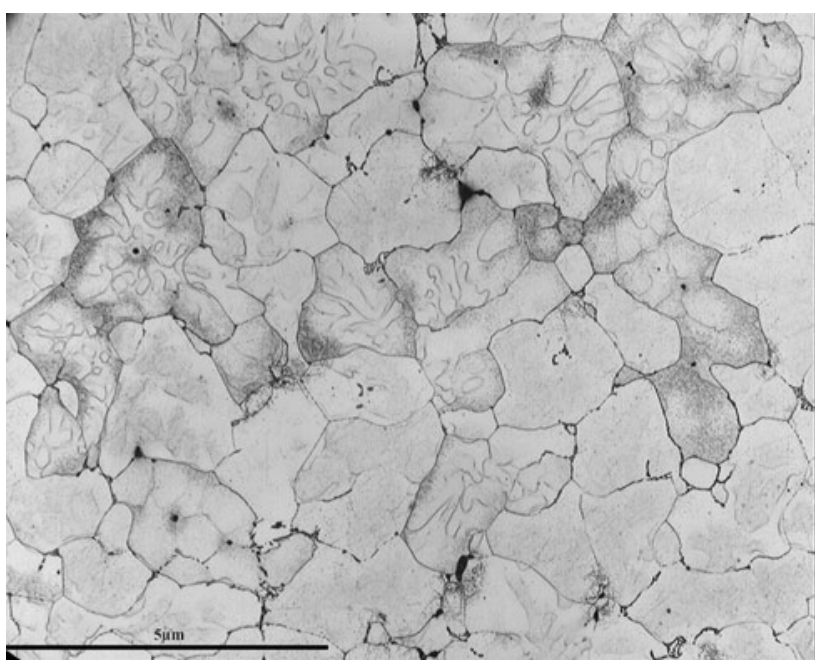

Fig. 7 Representative microstructure of transverse section of rightside fork leg

material led to the component hardening to $28 \mathrm{BHN}$ higher than the standard value.

Metallographic Analysis

The sectioned piece used for hardness testing was also prepared for metallographic inspection. Figure 7 is a micrograph of the casting which demonstrates a dendritic microstructure within grains, as well as the presence of shrinkage voids. As an age-hardenable aluminum alloy, the aluminum matrix will have precipitated intermetallic phases dispersed throughout; these phases will appear gray and black, as seen in Fig. 7, according to a comparative microstructure which was etched by Keller's reagent [4]. The Chinese-script phase is suspected to be $\mathrm{Mg}_{2} \mathrm{Si}$, a common constituent in aluminum alloys [5]. The remnant interdendritic phases are likely silicides, aluminides, and chromates $[4,5]$. Black phases dispersed throughout the grains could be $\mathrm{Mg}$ and $\mathrm{Zn}$ coring [4].

Figure 8 demonstrates the microstructure of the casting at a lower magnification and further illustrates the proliferation of voids within the casting. These defects represent pre-existing surfaces or cracks within the component, where incomplete solidification occurred during the casting process. These defects are common to modern aluminum castings, even high purity castings that undergo hot isostatic pressing (HIP). The presence of these defects throughout the component represent low-energy paths for crack propagation.

\section{Fractographic Analysis}

Visual inspection of the primary fracture surfaces (denoted as A and B) revealed both of them to be granular (Fig. 9), 


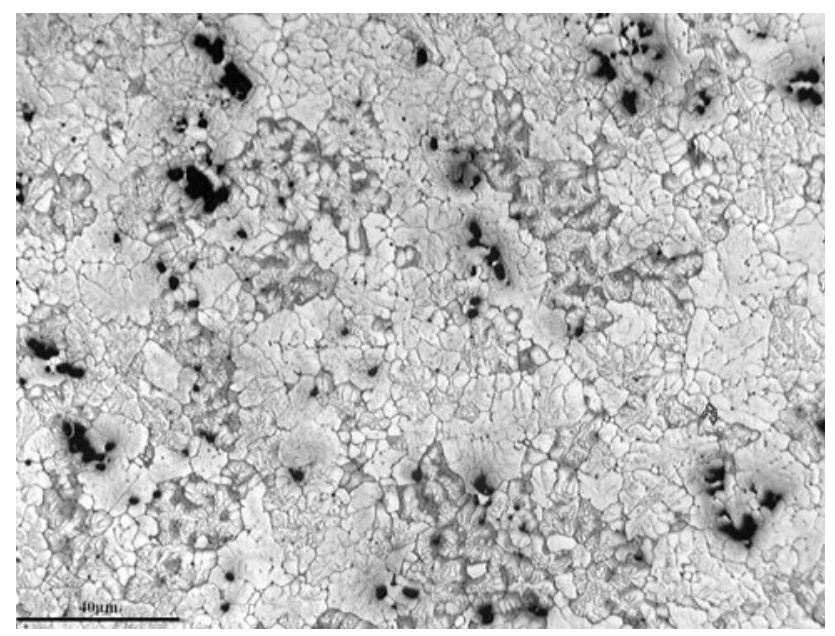

Fig. 8 Microstructure of longitudinal section of right-side fork leg, demonstrating the presence of shrinkage voids

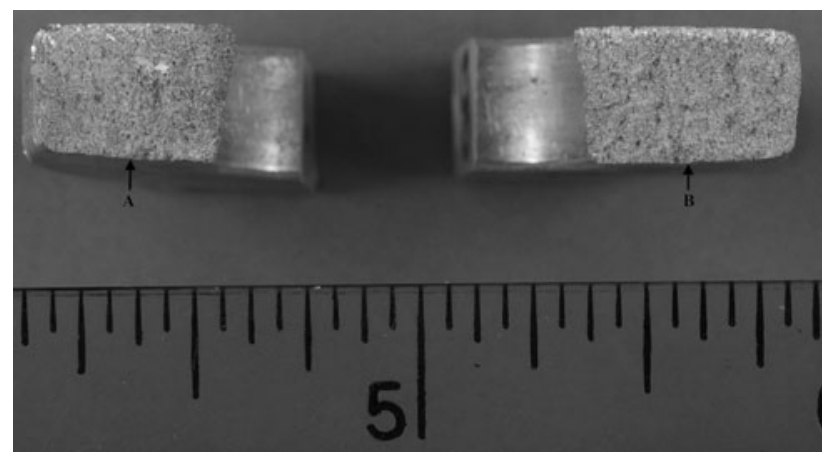

Fig. 9 Top view of primary fracture surfaces A and B

which is characteristic of brittle mechanical behavior of a material; the correspondent fracture surfaces of A and B that were on the left-side fork leg were abrasion damaged in the subsequent moments after the primary fracture occurred. In contrast, the morphology of the surfaces was deformed (Fig. 10), possibly indicating that some the material exhibited some plasticity before rupturing. Figure $11 \mathrm{dem}-$ onstrates the flat, undeformed morphology of the correspondent secondary fracture surfaces, denoted as C and D, which emanate from the remnant tailwheel fork body and the right-side fork leg, respectively. This morphology indicates that a very limited amount of plastic deformation occurred prior to abrupt failure; these fracture surfaces are also granular and lustrous (Fig. 12). The propensity of this alloy to brittle fracture is also reflected in limited tensile ductility, usually quoted for this alloy at approximately $4 \%$ [1].

SEM of the primary fracture surfaces revealed characteristics of two types of fracture morphologies, intergranular fracture and transgranular microvoid coalescence, indicative of a mixed mode [6]. Intergranular cracking and cleaved intermetallic particles are brittle

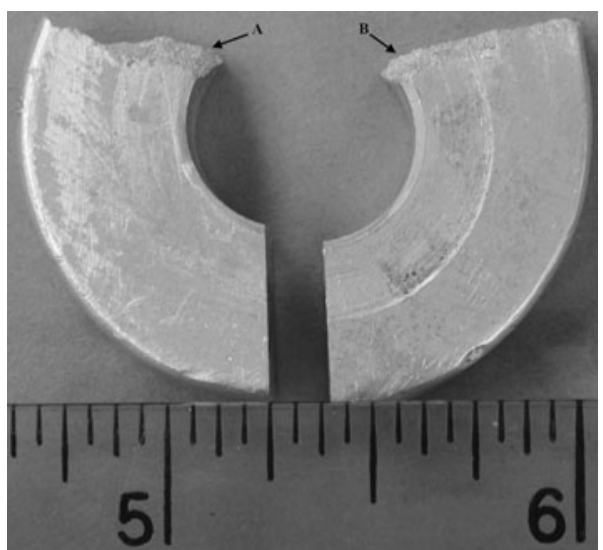

Fig. 10 Profile view of primary fracture surfaces A and B

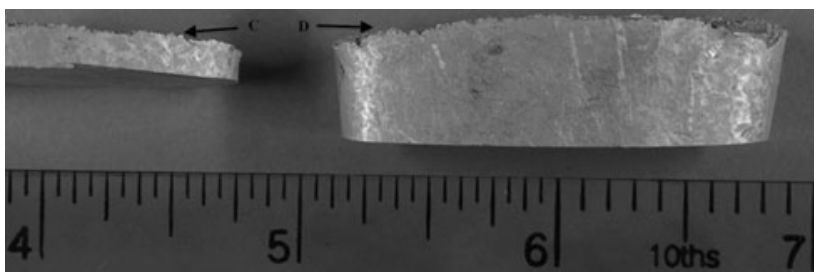

Fig. 11 Profile view of secondary fracture surfaces C and D

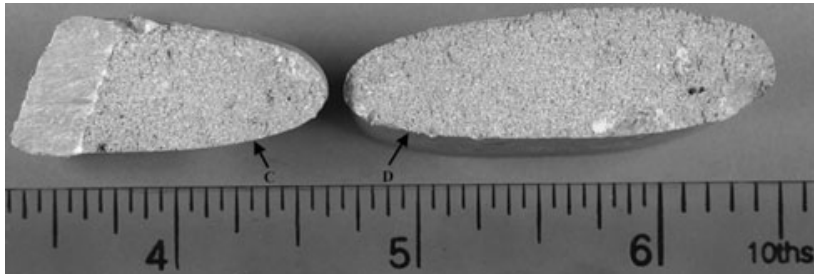

Fig. 12 Top view of secondary fracture surfaces C and D

fracture in nature, as opposed to the dimpled cellular regions of ductile fracture in the matrix (Fig. 13). The exposed arms of dendrites (Fig. 14) within voids substantiate the claim that the voids seen in the micrographs and SEM images are indeed shrinkage voids, a common feature in aluminum castings [7].

SEM of the secondary fracture surface revealed characteristics of one type of fracture morphology: intergranular fracture. Intergranular cracking and cleaved intermetallic particles (Fig. 15) indicate that the material was unable to deform as crack propagation occurred intergranularly during failure.

Both primary and secondary fracture surfaces demonstrate the presence of intermetallic particles within the intergranular and interdendritic regions.

\section{Stress Analysis}

As noted earlier, the component was drawn from measurements and extrapolated dimensions (Fig. 4); a FEA 


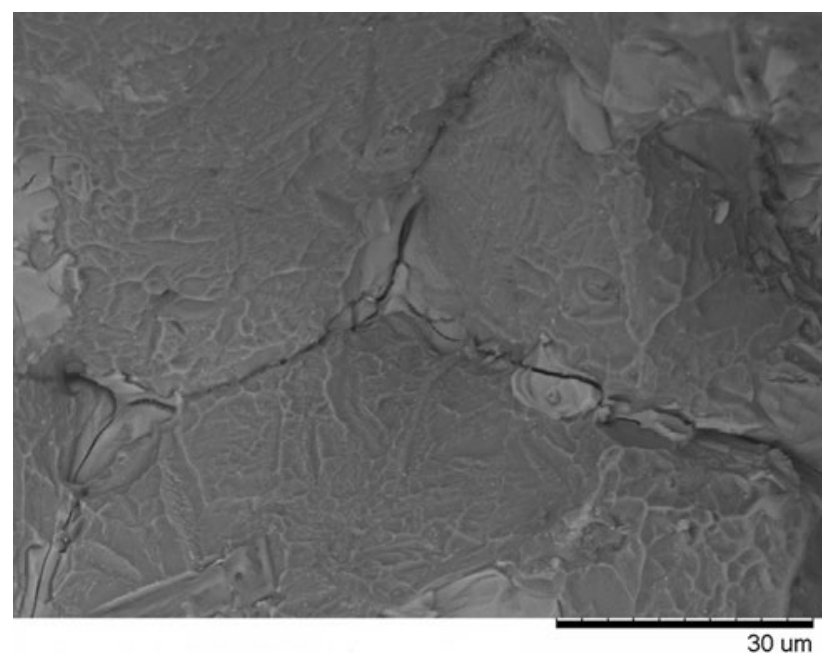

Fig. 13 Fractograph of sample A, demonstrating mixed mode fracture

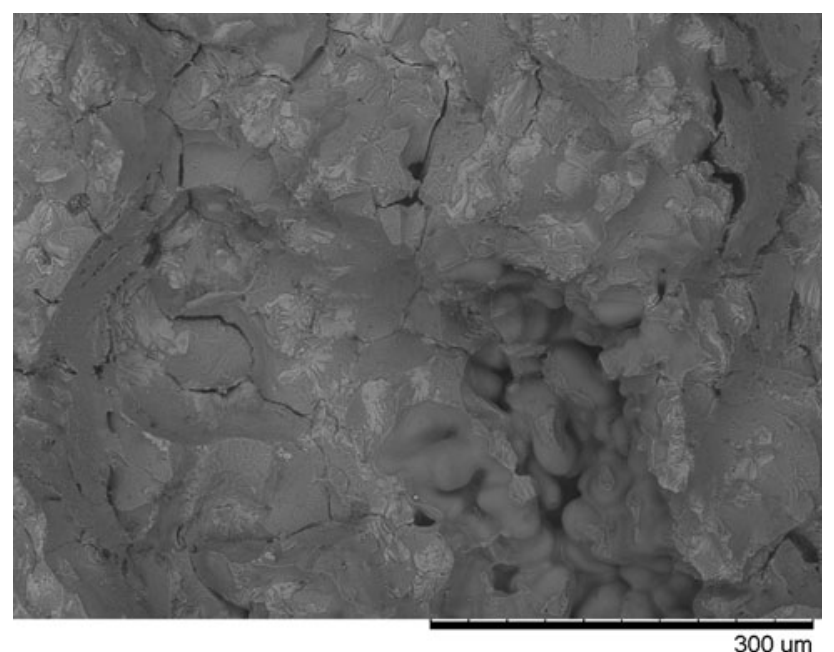

Fig. 14 Fractograph of sample A, demonstrating exposed dendrite arms within shrinkage voids

was subsequently performed. Figure 16 demonstrates a relative-stress grayscale map of the component under the compressive load of the airplane's weight, with a scheme of dark to light gray indicating increasingly higher stresses. The regions of highest increased stress, on compressive loading, are in the lightest gray and occur around the pin joints and at the fillet radii of the fork legs, as well as along the region that connects the fork legs to the body of the component. It is important to note that the grayscale map is not subject to absolute stress values, but rather relative stress magnitudes, which allows for a dimensionless interpretation and evaluation of the stresses within the component on compressive loading.

The primary fracture surfaces are aligned along the high stress regions around the pin joints, which indicates that the component failed where it was weakest in design.

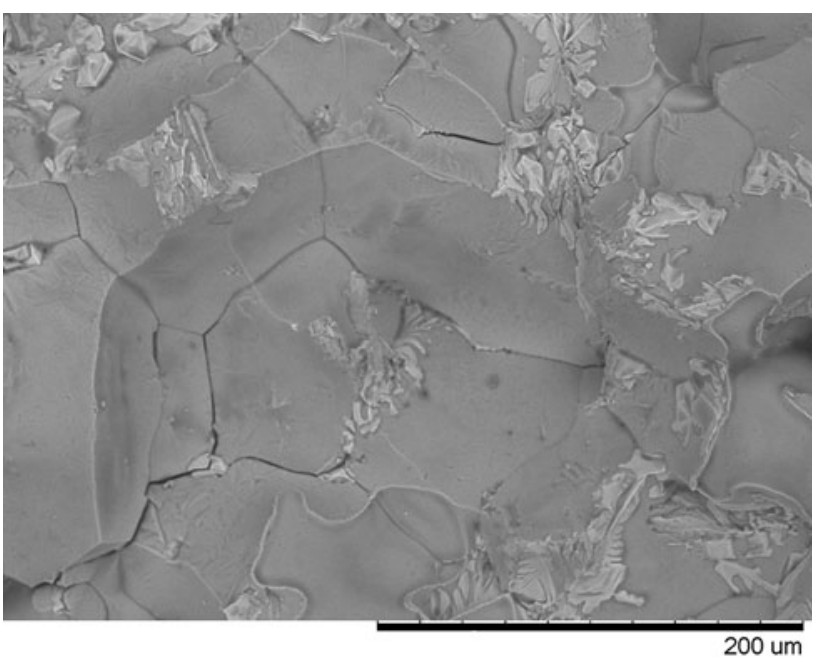

Fig. 15 Fractograph of sample C, demonstrating intergranular fracture

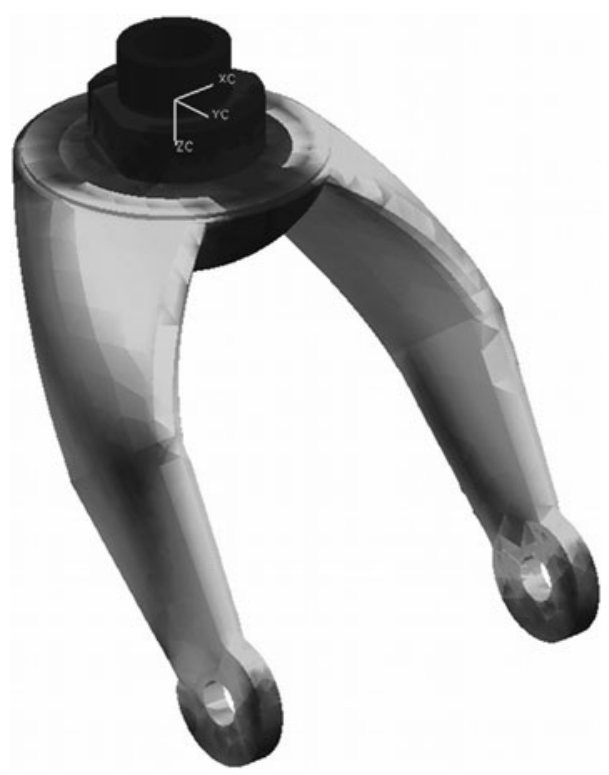

Fig. 16 FEA relative-stress grayscale map of the component under compressive load

\section{Conclusion}

In conjunction with the pilot's interview, the as-received documentation demonstrates that the following series of events could have occurred: after landing and moments before the airplane came to a full stop, the left-side fork leg failed at the axle pin joint (Fig. 2), which momentarily shifted the back-end weight of the airplane onto the remnant right-side fork leg. This right-side fork leg subsequently failed along its length due to overload, completely detaching the tailwheel from the airplane 
altogether. As the airplane came to a full stop, the remnant fork leg portions (the left leg's being longer) suffered attritional damaged from contact with the landing strip asphalt. Figure 3 supports this extrapolated series of events, as both remnant leg portions are abrasion damaged along the same plane, to the same level, with the right leg portion demonstrating part of the original secondary fracture surface.

The fact that the component's hardness was up to 28 BHN harder than the usual or expected value of as-cast, AA 712.0 in the T5 temper condition, supports the theory that the component over-aged after 54 years in service and failed under normal operating stresses. Two crucial stressconcentrating factors exacerbated these normal operating stresses and made the material rapidly overload: (1) the deleterious effect of shrinkage porosity, which created numerous surfaces within the material and acted as preferred paths for fast crack propagation, and (2) the increased presence of brittle, intermetallic aging products within the component.

In spite of the metallurgical deficiencies documented in this study, the tailwheel fork functioned more than 50 years. In the absence of any fractographic evidence indicative of sub-critical cracking, the only time-dependent contribution to this failure was the over aging and gradual reduction in both the tensile ductility and fracture toughness of the fork. The stress concentration conditions inherent to the design, coupled with dispersed shrinkage voids and intermetallic particles, contributed significantly to the fracture of the tailwheel fork.

Acknowledgments The authors of this article would like to sincerely thank the following individuals for their assistance in this work: Christopher Aguayo, Christopher Bradley, Damian Marrufo, Nayeli Camacho, and Kristian Ortiz.

\section{References}

1. Standard Specification for Aluminum-Alloy Sand Castings, B26/ B26M, 2009. ASTM International, West Conshohocken, PA (2009). doi:10.1520/B0026_B0026M-09, www.astm.org

2. Standard Practice for Heat Treatment of Aluminum-Alloy Castings from All Processes, B917/B917M, 2009. ASTM International, West Conshohocken, PA (2009). doi:10.1520/B0917_B0917M-09, www.astm.org

3. Hatch, J.E. (ed.): Chapter 8: properties of commercial casting alloys. In: Aluminum: Properties and Physical Metallurgy, pp. 338, 347. ASM, Metal Park, OH (1984)

4. Mehl, R.F., Bankard, M.H., Federico, A.M., Fortin, P.E.: Microstructure of aluminum alloys. In: Lyman, T., Boyer, H.E., Carnes, W.J., Unterweiser, P.M., et al. (eds.) Metals Handbook, Vol. 7: Atlas of Microstructures of Industrial Alloys, 8th edn., p. 260. ASM, Metals Park, OH (1972)

5. Mondolfo, L.F.: Chap. 7: Constituents, Metallography of Aluminum Alloys, p. 181. Wiley, New York, NY (1943)

6. Miller, B.A.: Overload failures. In: Becker, W.T., Shipley, R.J. (eds.) ASM Handbook, Vol. 11: Failure Analysis and Prevention, p. 678. ASM International, Metals Park, OH (2002)

7. Failures related to casting. In: Becker, W.T., Shipley, R.J. (eds.) ASM Handbook, Vol. 11: Failure Analysis and Prevention, p. 129. ASM International, Metals Park, OH (2002) 